\title{
RE-DESIGNING THE DESIGN BRIEF AS A DIGITAL LEARNING TOOL WITH PARTICIPATORY DESIGN APPROACH
}

\author{
Dr. Duysal DEMIRBAS \\ ORCID: 0000-0003-1130-1469 \\ Faculty of Architecture and Design \\ Eskisehir Technical University \\ Eskisehir, TURKEY \\ Dr. Sebnem TIMUR OGUT \\ ORCID: 0000-0003-2919-7364 \\ Faculty of Architecture \\ Istanbul Technical University \\ Istanbul, TURKEY
}

Received: 19/05/2019 Accepted: 26/08/2019

\begin{abstract}
Today, industrial design education is faced with a new group of students who have met daily life technologies from a very early age. The transformations in educational environments are becoming more and more important for project-based and student-centered design education model. Understanding the needs and expectations of the changing student profile has become essential for design education, which puts new and original outputs as the main objective. Students' expectations of having a say in their own learning environments also provide an important opportunity for them to play an active role in the focus of this change. The aim of this study is to determine the design criteria of a new learning tool in line with the needs and expectations of the new generation industrial design students with a student-oriented approach. Participatory Design workshops were organized to expose expectations of the current learners about a new Design Brief in a digital and online medium. In this qualitative study conducted with participatory design method, gamification elements were used to increase students' motivation, interest, and participation. Design criteria for a new generation design brief have been introduced with participatory design method. All suggestions were found to indicate a more interactive structure depending on the variable and cyclical structure of the design.
\end{abstract}

Keywords: Design education, new millennium learners, participatory design, design brief, gamification.

\section{INTRODUCTION}

It has become more and more important to determine the expectations and needs of a new generation that has experienced daily life technologies since the early ages in new educational environments. While Pedro (2009)defines this generation as New Millennium Learners, he draws attention to the fact that these students have different expectations, needs and characteristics than previous generations.

It is seen that the use of technological facilities frequently in educational environments changes/ transforms the way we transfer of course contents and the tools and environments used in lessons. This rapid change also necessitates the systematic management of the learning. In design education, which is based on a projectbased learning model, the intersection of learning management and project management is becoming more and more difficult for design education. It is seen that there is an attempt to use "Design Brief" as learning management tools in design education (Demirbas \& Timur Ogut, 2018). Design Brief is a printed document that consists of the project's theme and basic information about how the process will be handled. Phillips (2004) refers to Design Brief as an explanation of the project scope. Considering the habits of New Millenium Learners; using mobile technologies such as smartphones, tablets and tablet PCs, it is becoming increasingly important for this document to be in an environment that is instantly accessible, shareable and even rearrangeable. 
In parallel with this change and transformation in learning environments, the industrial design discipline is also repositioning itself as a discipline in which multiple fields work together (ICSID, 2015)In this transformation, the actors of the design process are actively involved in processes that vary from designer to end-user. In terms of occupation, the involvement of people from different fields in the design process is considered as an element enriching the process. While the tools used in these environments in design education are often designed by academics, it is seen that the students who are the end-users are not involved as decision-makers and stakeholders in the design process of these tools. Especially in recent years, both the transformation of the definition of the profession and the transformations of the student characteristics, expectations and needs (Pedro, 2006) point to the need for a new generation education environment (Prensky, 2001).In this study, we will share the results of a Participatory Design workshop which aims to reveal the needs and expectations of the new generation learners through the "design brief" which is used as a basic tool to share the project subjects with students and which includes and determines the basic elements of the process in industrial design education.

The aim of this study is to set out the basic criteria for a new generation brief to be used in design education with Participatory Design methods and tools. Findings will be presented under the titles of content and formal suggestions as components that can guide a new generation of "design brief".

\section{LITERATURE REVIEW}

\section{Design Brief}

Design studio courses in Industrial Design education are handled within a learning-centered approach with a project-based learning model that will form the basis of design education. The "Design Brief", which includes sections such as project prospects, purpose and scope, process expectations, evaluation criteria and working schedule, is one of the key components of this process (Jones \& Askland, 2012; Ryd, 2004) The Design Brief in an educational context has two intended users: an academician who prepares the document and the student who takes this brief. The strategic differences between teaching and learning processes also change and differentiate the way these two stakeholders use the Design Brief (Demirbas \& Timur Ogut, 2018). With this document, the academicians tell the students how the expectations and process will be handled and the students can act accordingly by being informed about the criteria and time planning for the project.

In-studio education, the Design Brief is very important in terms of being the first step of the project process. Not only does it starts the process which the students and project coordinator will work together, but it also includes the steps with which the process will be carried out. As expressed by Philips, despite its various names, the brief is essentially a description of the scope of the project; it is a document that identifies the calendar of the project, the quality of the resulting product, and helps to control the project and decision process (Phillips, 2004)

It is seen that students' relations with the Design Brief are becoming weaker and not used in the way that they are predicted. In Design Education, it may be difficult for a design brief to meet expectations in the process depending on its current structure(paper-based and rigid) while transferring both the content of a project theme and the management role (Demirbas \& Timur Ogut, 2018). Lawson (2005)states that the traditional design process should begin with the preparation of the design brief and defines this document as a "start". However, Nina Ryded (2004)draws attention to the fact that the design brief should be treated as an information process which develops gradually rather than being well prepared at the very first stages. This viewpoint offers significant potential for meeting the expectations of new millennium learners to use the tools in learning environments in a more interactive way. 


\section{Participatory Design}

How, in the design process, rather than the product itself, users started to come to the forefront, while in the learning environments, the shifting role of learners to the center is fed by the same paradigm shift; a more democratic participatory approach.

Participatory Design is defined as non-designers and designers contact with any product or system working together in the design process(Sanders, Brandt, \& Binder, 2010). The Participatory Design expresses, in the shortest sense, an approach to the right of persons to be influenced by the results of a design to have a say in the design (Manzini \& Rizzo, 2011). In this context, we can say that opportunities offered by Participatory Design in the professional field, should also be evaluated in design education. Participatory Design is also defined as a collective process where designers, users, and other stakeholders often come together through workshops (Hussain, Sanders, \& Steinert, 2012)

In the discussion of whether the Participatory Design is a method or an approach, Spinuzzi (2005) treats Participatory Design as a methodology with its own methods and tools, not as an approach, and says that "Participatory Design is research". While the Participatory Design is not different from social science research procedures as a research approach, it is similar in terms of other qualitative research approaches and methods and tools (Bergold \& Thomas, 2012). In the participatory design, the users, ie the participants, are found as experts of their experience (Bedir Eristi, 2017; Visser, Stappers, van der Lugt, \& Sanders, 2005). While the involvement of learners in the design processes of the learning environment is possible through Participatory Design methods and tools, this approach not only contributes to meeting the needs but also contributes to the understanding of learning processes (DiSalvo, Yip, Bonsignore, \& DiSalvo, 2017)

Workshops are also an important tool for informing people about the current problem and sharing and visualizing their ideas and values among design-solution proposals(Ahn, 2007). The importance of workshops in terms of Participatory Design is often explained by the fact that participating actors become part of the design social process (Luck, 2003a), actively participating in the discussion, debate and decision of the (Luck, 2003b; Malinverni, Mora-Guiard, \& Pares, 2016; van Manen, Avard, \& Martínez-Cruz, 2015) The learners, who are one of the two users of the brief, assume a participatory role as non-designer of a brief, though they are only using the brief as they never took an active part in the design process.

\section{Gamification}

Gamification has been defined as a set of philosophies and methods aimed at making these activities more effective and useful by using the concepts and actions associated with playing games within activities outside the game context (Hamari, 2013; Muntean, 2011; Sierra, 2013). Karl Kapp (2012) defines Gamification as "the use of game-based mechanics, aesthetics, and game thinking" to motivate people to connect, to motivate them to take action, to encourage learning and to solve problems.

Kevin Werbach(2015)discussed all the elements of gamification in three dimensions as Dynamics, Mechanics, and Components under the title of "Gamification Toolkit". Yilmaz (2015) details the three-dimensional structure of Kevin Werbach and lists the elements of all dimensions as follows. 


\begin{tabular}{l|l|l}
\hline \multicolumn{2}{l}{ Gamification Elements } \\
\hline Avatar & Challenge & Relations \\
Achievements & Player level & Collecting resources \\
Fighting & Award & Earnings \\
Team & Rewarding & Winning status \\
Interactions & Score & Collections \\
Feedback & Badges & Rules \\
Missions & Virtual Savings - Money & Leadership chart \\
Goals & Freedom of choice & Teamwork \\
Storytelling & Turn & Competition \\
Open content & Social Graph & Luck factor \\
Progress level & & \\
\hline
\end{tabular}

Figure 1. Gamification elements

Simulation of real-life environments in-game environments is very important in terms of enabling the new generation to take risks to the trial-error path in these environments, to be more courageous in decision making, and to enable problem-solving skills to be developed through repeated attempts in different environments (Kapp, 2012)(Klopfer, Osterweil, Groff, \& Haas, 2009). The full evaluation of the gamified learning environments, which are seen as an important tool in the development of skills such as creative thinking and problem solving, will enable us to explore common themes that may be used in meeting the objectives of the design studio courses.

While gamification can be used as a research method by itself as an environment in which the participant participates actively and in-depth data is obtained (Bedir Eristi, 2017) it has been used as an element related to the tool kit in conducting Participatory Design workshops in this research. Gamification has also been chosen as a tool in accordance with the conceptual framework of the research to determine the approach to be used in delivering and communicating the content to be produced in an online environment. The aim of this study is not to obtain a gamified online brief, but to reveal the expectations and suggestions of the learners for a brand new design brief in an online medium.

\section{METHODOLOGY}

This study aims to reveal the expectations and needs of the new generation students in reconstructing the design brief as a digital learning management tool. In accordance with a student-centered approach, to re-design the Design Brief, not for learners but with them, Participatory Design has been implemented to provide a basic model for this study. The "gamification" approach has been used as an element that motivates participants to reveal the expectations and needs of new millennium learners who have been familiar with digital games and gamified mediums since early ages.

The qualitative research process was carried out with the Participatory Design approach to reveal critical design principles of a new learning tool for new generation industrial product design students to be used in design studio courses with a learning-centered view. The importance of Participatory Design approach in this study is allowing the researcher to use special methods and tools in his / her research focusing on design problems related to learning environments. Participatory Design workshops were organized to expose expectations of the current learners about the creation and sharing of the Design Brief in a digital and online medium.

A Participatory Design workshop titled "Brief Re-Edited With Gamification Elements" has been carried out between 21-23 September 2016. A total of 11 students from different universities attended the workshop which was held within the scope of "National Design Research Conference (UTAK) organized by the Faculty of Architecture at METU.

Gamification approach has been used as a tool to bring out and also to help express the expectations, needs, and recommendations of new generation industrial product design students. In order to determine the priority criteria of a new generation learning tool suitable for the interactive and dynamic structure of the 
design process, the game mechanics and components experienced by the students from early ages have been used. Suggestions for the design of a tool that students will use were presented with the help of basic concepts and items used in gamified applications.

\section{Participants}

The call for participation in the workshop has been shared with the students via the conference website. In parallel, a poster was prepared to be shared on social media and shared through the researcher's personal social media account. In the Participatory Design approach, the contribution of the various stakeholders in the domain of the problem to be solved is expected in the solution process, but it is not possible to include all of the contributors in the process (Menconi, Grohmann, \& Mancinelli, 2017). As the research is designed to reveal the expectations and needs of the current design students, participants have been identified as graduate students studying in industrial design in Turkey. Within the framework of the potential contribution of needs and expectations of students that are expected to be unveiled at the workshop for a new brief the most basic criterion was to take the "Design Studio" courses to attend Participatory Design workshop.

After the participant list of the workshop was shared by the organizing committee, a Facebook event page was used to invite the participants. Brief information about the workshop and the communication information of the workshop executives are shared on the page. A short informative text and a list of required materials were shared with the e-mail addresses of all participants in the workshop attendance lists and the workshop

\section{Data Collection and Analysis}

Video and photo-shootings were used in the workshop documentation. The interviews of the participants along the presentation of design proposals were recorded as a video with permission from the participants. (Buur, Binder, \& Brandt, 2000; Malinverni et al., 2016) Poster presentations, oral presentations, and discussions were used to gather data.

During the workshop and during the presentation of the design proposals that emerged as a result of the workshop, video recording was taken. A content analysis method was used to examine the relation of each group with the design proposal and the proposal of the expressions used in the presentations.

\section{The Toolkit Development Process for a Participatory Workshop}

A toolkit was developed for the Participatory Design workshop. The key features of the new millennium learners have been considered in the design of the kit. "When developing tools to be used in the workshop, the design process must be simplified as in a design process guide, providing a participant role-level that the project participants can manage, and more diverse and sensitive items"(Ahn, 200). A special toolkit has been designed for diversity and precision in increasing participation and motivation. In the design of toolkits, cards and items printed in the A4 format were used.

In the Participatory Design process, card usage has a wide usage potential in terms of ease of use and ease of production (van den Hoven, Vermaas, \& van de Poel, 2015) While Wolfel and Merrit( 2013) (2013) classified the cards used in the design process divided in three;

1. General-purpose

2. Customizable cards and

3. Specific content-specific cards

It seems that customizable cards contain guidelines that describe how non-designers use cards in participant design processes (van den Hoven et al., 2015), as participants can add new cards and change cards(Wolfel $\&$ Merritt, 2013). The cards are also used for different purposes such as idea generation, inspiration, participation, empathy and to overcome the problems that arise in a design process(Wolfel \& Merritt, 2013).In designing the cards to be used in this workshop, both a customizable card and a specific content card design approach have been used. In the design of cards, the "gamification approach" which is frequently used especially for the new generation learners. 
The gamification themed cards used in the workshop were used as a tool to enable students to discover and express their needs and expectations.

\section{Gamification Card Set Design}

The tool kit used in the workshop consists of card decks and a design brief. Elements brought together as Gamification toolkit for cards are divided into categories by being categorized by the same headings. There are 40 cards on each card deck. 3 of them contain general contents, 31 of them contain Gamification elements. There are 6 blank cards on each deck.

The Design Brief, which is used as the most common tool of transferring the project theme in industrial design departments, has been prepared specifically for use in this workshop by using existing design brief templates (, 2010), in accordance with the learning outcomes of the Product Design IV course in the fourth spring semester of Anadolu University undergraduate programs ("Akademik Dersler - Tanitim," n.d.).The brief titled "Cooking Unit" consists of 3 pages in total A4 format. The brief was distributed in print as a participant.

\section{Execution of Workshop}

The workshop was conducted at the METU Faculty of Architecture where the conference took place. The four-session workshop lasted four hours in total.

\section{Part One}

The first 30 minutes of the workshop were devoted to informing the participants about the meeting and the workshop. Information on the participants of the workshop, the purpose of the participant design workshop and the use of the data to be obtained from the workshop were shared with the students. A presentation (powerpoint) on basic concepts and items related to Gamification has been made with regard to the card set used in the workshop. A presentation was made for each card, explanation, and examples of the role of the concepts in gamification are shared.

Participants were grouped by the workshop organizers. The first reason for the participants' working as a group is to prevent the close friendship relations of the students from the same university and class to the workshop to create a communication environment that can prevent their subjectivity at the point of expressing individual decision and recommendation in group work. Secondly, to encourage the emergence of new and different ideas as a result of group interaction and group dynamics of participants from different educational environments (Cokluk, Yilmaz, \& Oguz, 2011)

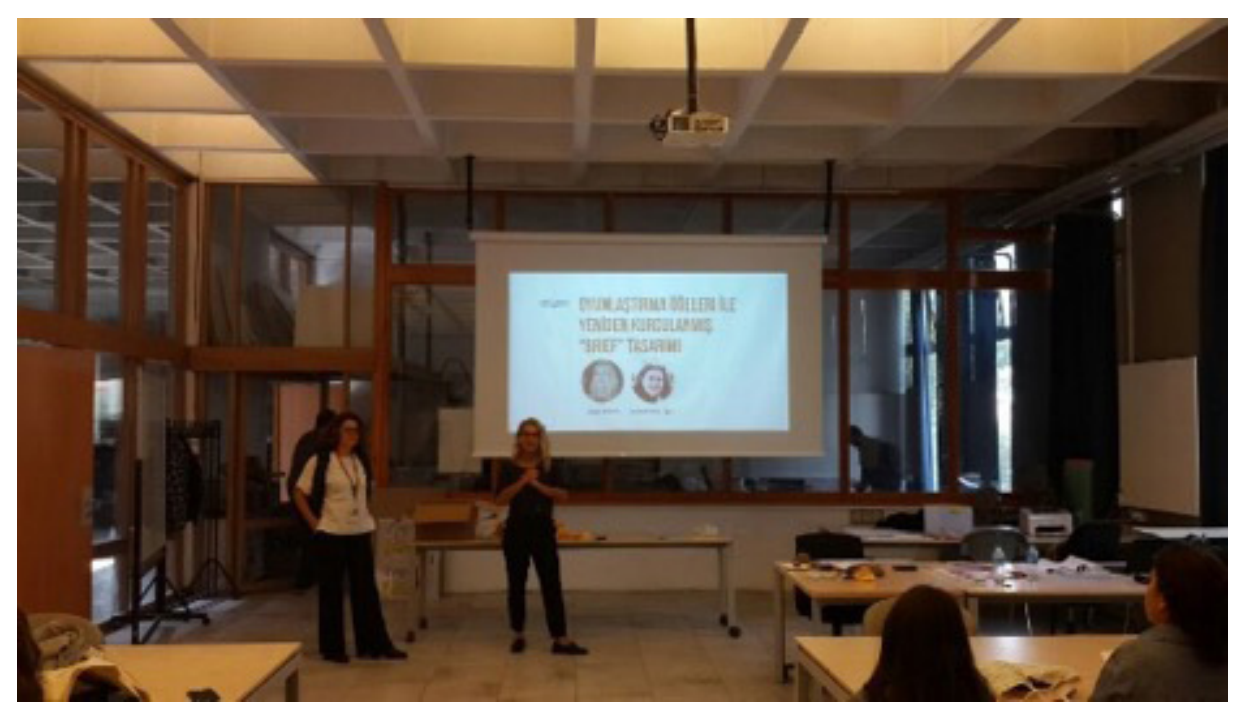

Picture 1. Information presentation about the workshop 
Cards previously prepared, containing gamification items were distributed to the students and explanations were made for the use of each item (Picture 1)

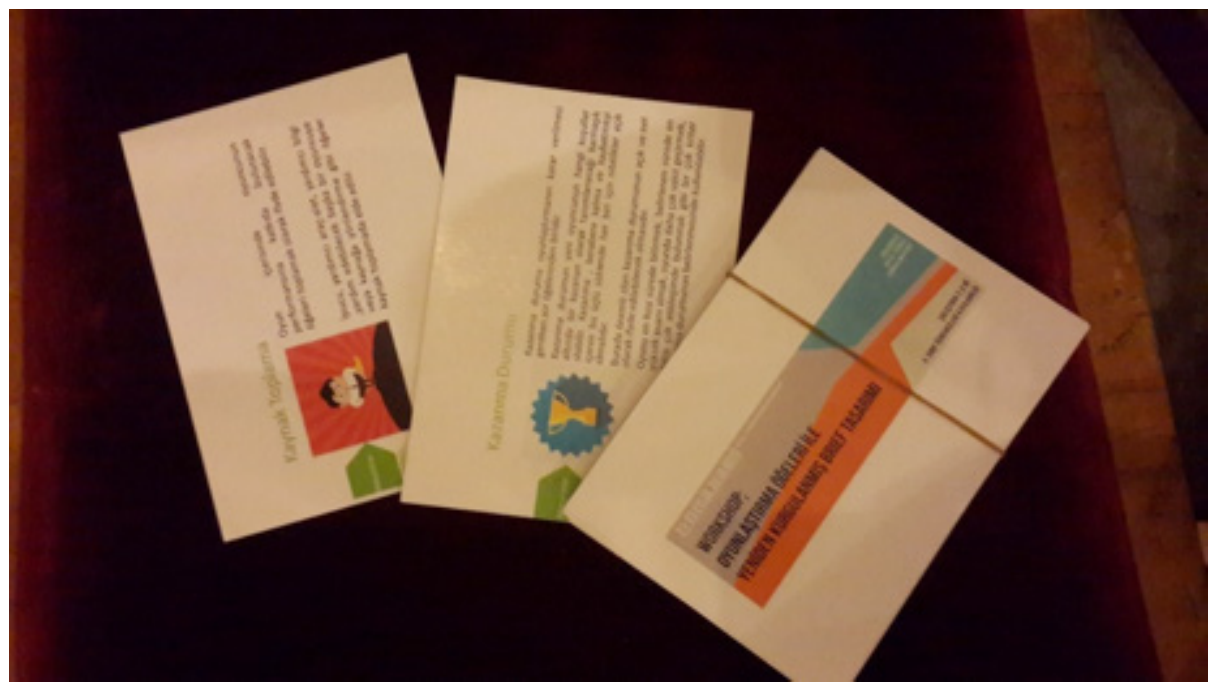

Picture 2. Set of cards distributed to the participants

\section{Part Two}

The printed "design brief" specially prepared for this workshop which is eligible for 3rd-grade students was distributed. The students were given 10 minutes to review the "brief". After this step, it is required to redesign the "brief" which is given in print with the Gamification cards present in the hands of the groups in the direction of their expectations and preferences. Participants were given blank cards so that their cards could reflect their own items. In the poster presentation, the students benefited from gamification cards and printed brief by cut-and-paste technique.

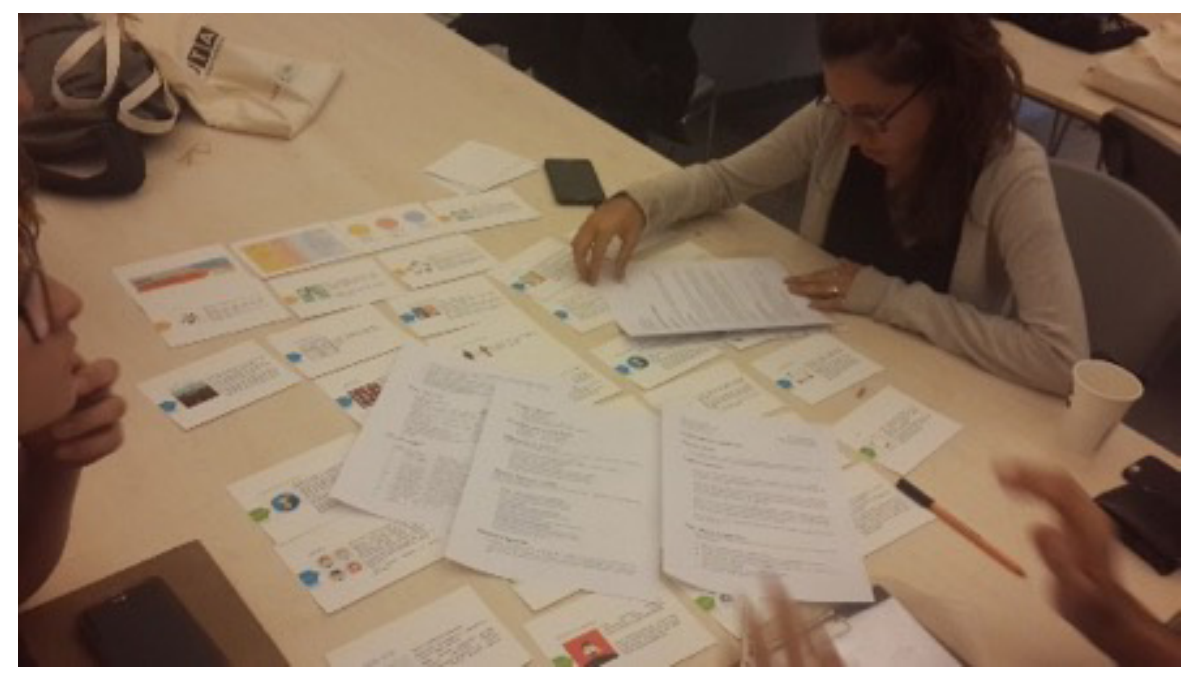

Picture 3. Sharing the printed brief with participants

\section{Part Three}

Students are asked to discuss how to recreate a new generation of the design brief with different media and tools. In this direction, students were asked to prepare a poster with a size of $50 * 70 \mathrm{~cm}$, expressing how a "brief" with their own preferences and anticipations should be conveyed in the delivery of project topics using gamification elements. The purpose of this poster session is defined as not to present itself as a design brief, but to highlight in which parts of the brief and for what purpose the Gamification elements are used. 
When students prepare their posters, they have cut and redesigned the cards distributed to them. They used the images and texts contained in the cards separately. They have resized the cards to include only the title of visual and short description. There are no restrictions on the tools to be used in the preparation of the posters.

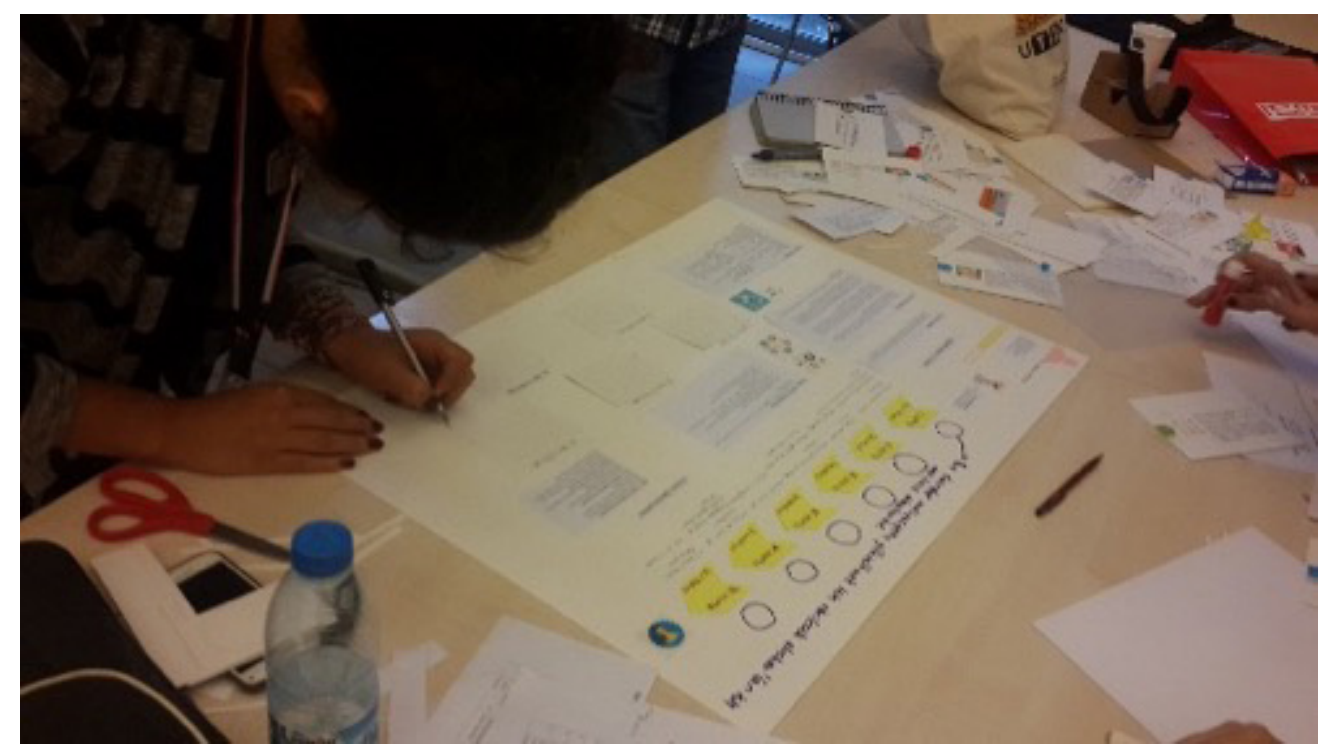

Picture 4. Poster preparation of students

\section{Part Four}

Students share oral presentations of posters they have prepared with other groups. During the presentation of each group, discussions have been held on the use/relevance of brief proposal and gamification elements with the participation of all students and executives involved in the workshop.

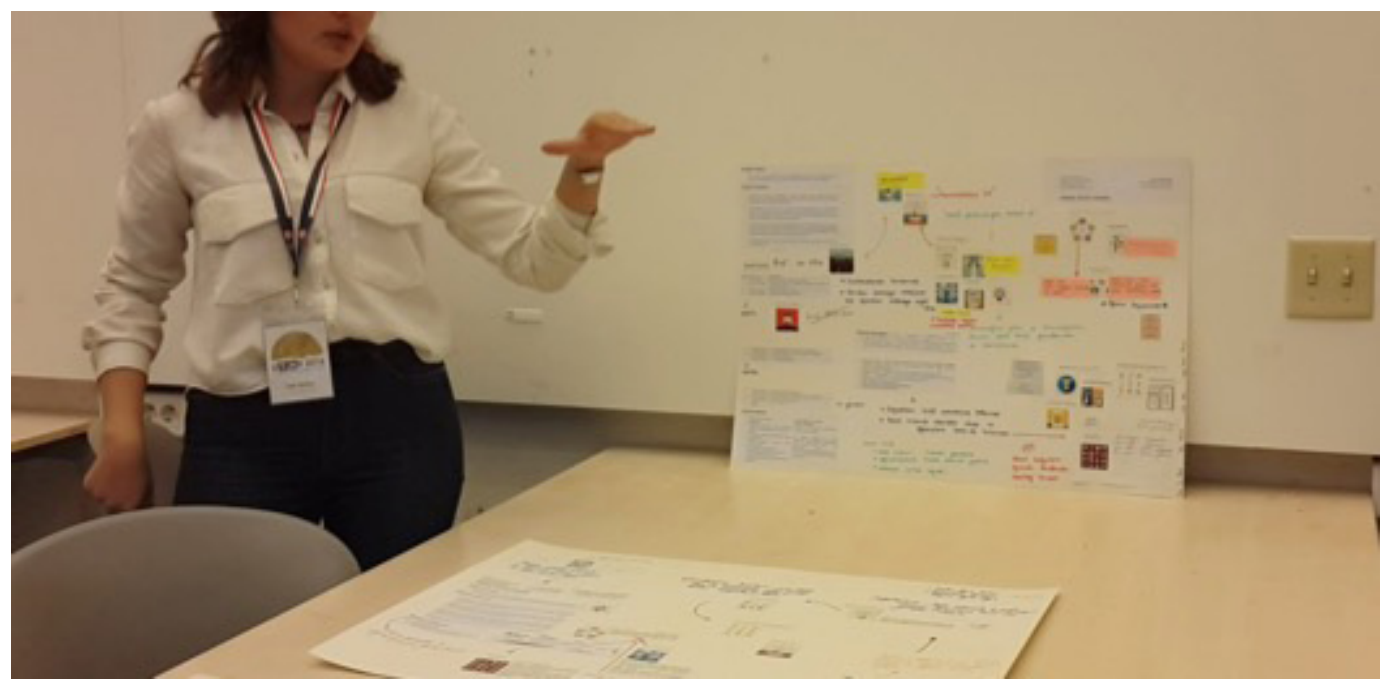

Picture 5. Presentations of student groups 


\section{FINDINGS}

In the following table, the principles that help us frame the design proposals for each group are shared due to video recordings, the workshop process and the notes taken by the project team during the presentation.

Table 1. Use of Gamification elements in Groups

\begin{tabular}{|c|c|c|c|c|}
\hline Gamification Elements & GROUP 1 & GROUP 2 & GROUP 3 & TOTAL \\
\hline 1: Avatar & 0 & 0 & 1 & 1 \\
\hline 2: Achievements & 0 & 0 & 0 & 0 \\
\hline 3: Fighting & 0 & 0 & 0 & 0 \\
\hline 4: Team & 0 & 1 & 0 & 1 \\
\hline 5: Interactions & 1 & 1 & 1 & 3 \\
\hline 6: Feedback & 1 & 1 & 0 & 2 \\
\hline 7: Missions & 1 & 1 & 1 & 3 \\
\hline 8: Goals & 1 & 1 & 1 & 3 \\
\hline 9: Storytelling & 0 & 0 & 0 & 0 \\
\hline 10: Open content & 0 & 1 & 0 & 1 \\
\hline 11: Progress level & 1 & 1 & 1 & 3 \\
\hline 12: Relations & 1 & 1 & 1 & 3 \\
\hline 13: Collecting resources & 0 & 1 & 0 & 1 \\
\hline 14: Earnings & 1 & 1 & 0 & 2 \\
\hline 15: Winning status & 0 & 1 & 1 & 2 \\
\hline 16: Collections & 0 & 1 & 0 & 1 \\
\hline 17: Rules & 0 & 0 & 1 & 1 \\
\hline 18: Leadership chart & 0 & 1 & 0 & 1 \\
\hline 19: Challenge & 0 & 0 & 0 & 0 \\
\hline 20: Player level & 0 & 0 & 0 & 0 \\
\hline 21: Award & 0 & 0 & 0 & 0 \\
\hline 22: Rewarding & 1 & 0 & 0 & 1 \\
\hline 22: Score & 1 & 0 & 1 & 2 \\
\hline 24: Badges & 1 & 0 & 0 & 1 \\
\hline 25: Virtual Savings - Money & 0 & 1 & 0 & 1 \\
\hline 26: Freedom of choice & 0 & 0 & 0 & 0 \\
\hline 27: Turn (turn) & 0 & 0 & 0 & 0 \\
\hline 28: Social Graph & 1 & 0 & 0 & 1 \\
\hline 29: Luck factor & 0 & 0 & 1 & 1 \\
\hline 30: Teamwork & 0 & 0 & 0 & 0 \\
\hline 31: Competition & 0 & 0 & 0 & 0 \\
\hline
\end{tabular}

\section{Group 1}

A total of 3 students participated in this group. In the first group, a total of 11 conceptions of Gamification have been used. 


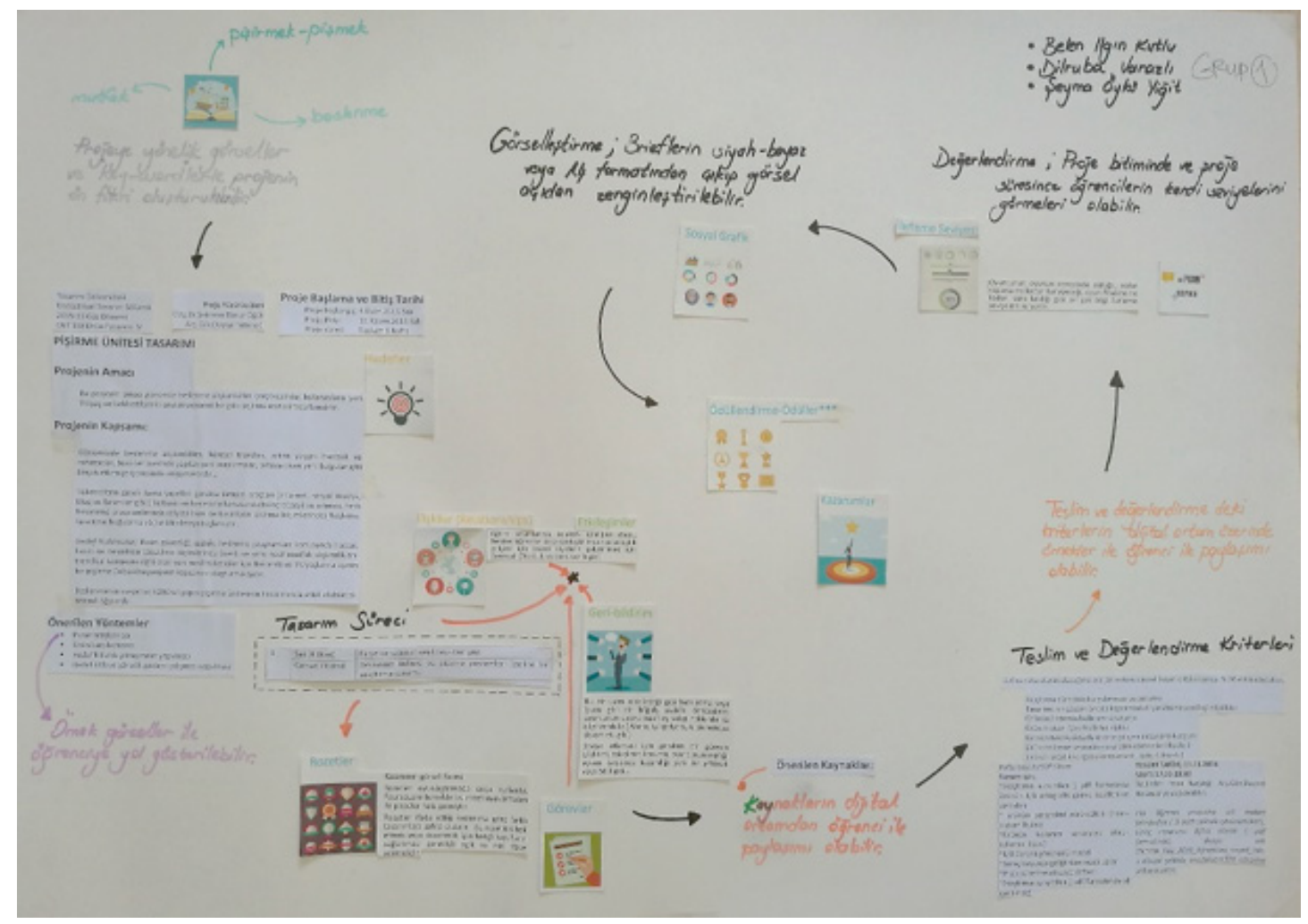

Figure 2. First group poster presentation

The group expressed the most important problem in the studio as time planning:

"The start and finish date is a big prelude to us.... what task we have to complete in the design process while we are going on ... what we would have achieved if we completed this task ...".

In the Brief Proposal, the things to be shared or delivered at the course hours in the work calendar section is referred to as "tasks" by the students. In relation to this, the expectation is that there should be a provision that can be obtained when the task is completed. The students cut the phases of the design process, which is divided into weekly work schedules, one by one and put them on top of each other, and they re-constructed that part as a printed standalone item to carry with them (Figure 3).

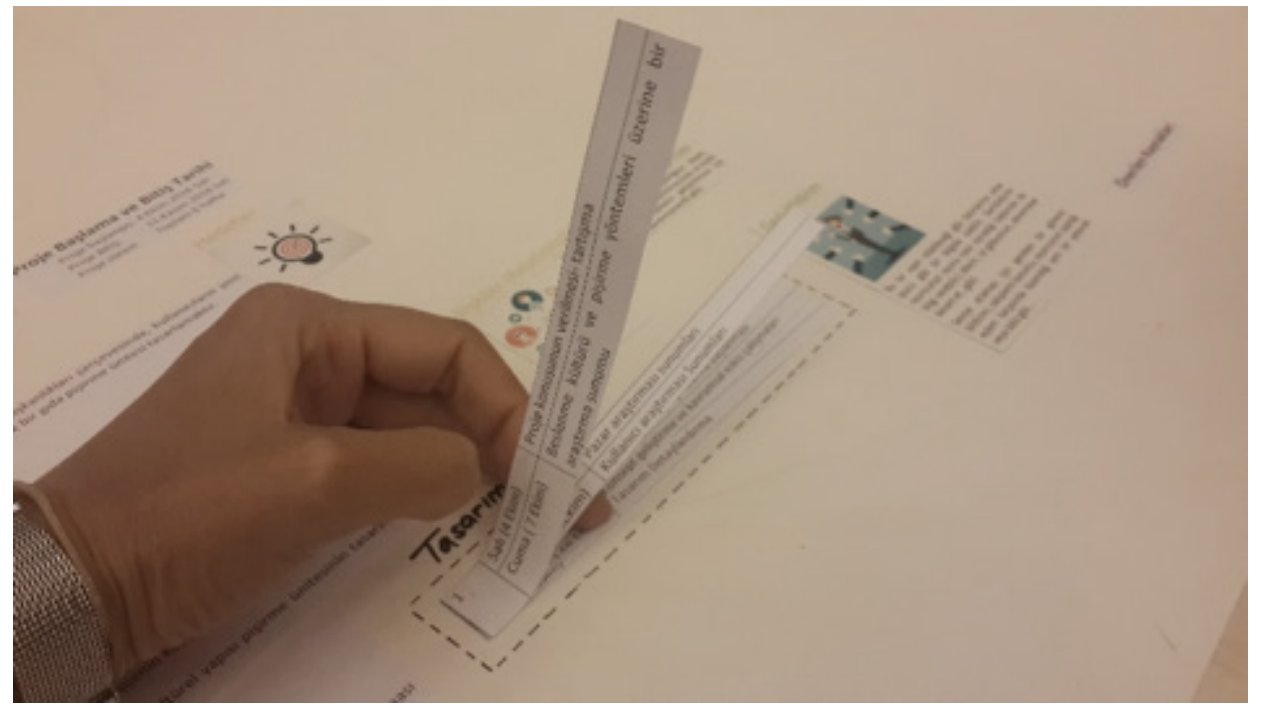

Figure 3. Separation of work calendar from a brief 
One of the suggestions for the project courses was that the academicians should explain the expectations by visual examples and share them in the digital environment. A similar expectation was expressed as the need to explain the issue when starting the project:

\section{"Small visuals can be used to explain the project like small keywords".}

The first group has been a proposal to share the resources that have been reached within the frame of individual or group researches made on the project subjects on a common digital platform. This recommendation is expressed using interaction and relationship elements (Figure 2). Instead of sharing the printed and printed resources, students have set criteria for digital accessibility and visual support. They stated that they expect to reach the samples or sources through the online links which will be shared through these environments.

"We do not go and search at the library, we do not read those books a lot, we all aim to provide access to most things via digital media".

Another student supported this expression as follows:

\section{"if the sources are shared on paper we never type those letters one by one online, we do not look at it} at all"

One of the basic expectations of the students is ensuring their design processes to be followed by academicians and immediate and continuous feedback on their learning situation. Students recommend a badged to be obtained if they complete the stages of the design process on a weekly basis in the studio and to be encouraged to express what they have been feeling to be doing or completing something. They express that feeling something like "completing" is an important source of motivation in the process.

One of the prominent expectations come out of the poster presentations and oral presentations are more visual elements to be used in briefs. The group spokesman stated this expectation:

"The briefs can be visualized a little bit more... as briefs come out of the same formats ... like always black and white.....not in the classic A4 format, the brief can be different.

It is seen that the use of visual elements for sharing the sources and examples is a visual expectancy for a new brief format, and the use of more visual elements in the writing-oriented briefs is an expectation for style.

\section{Group Two}

A total of 4 students participated in this group. In the second group, a total of 17 concepts of gamification were used.

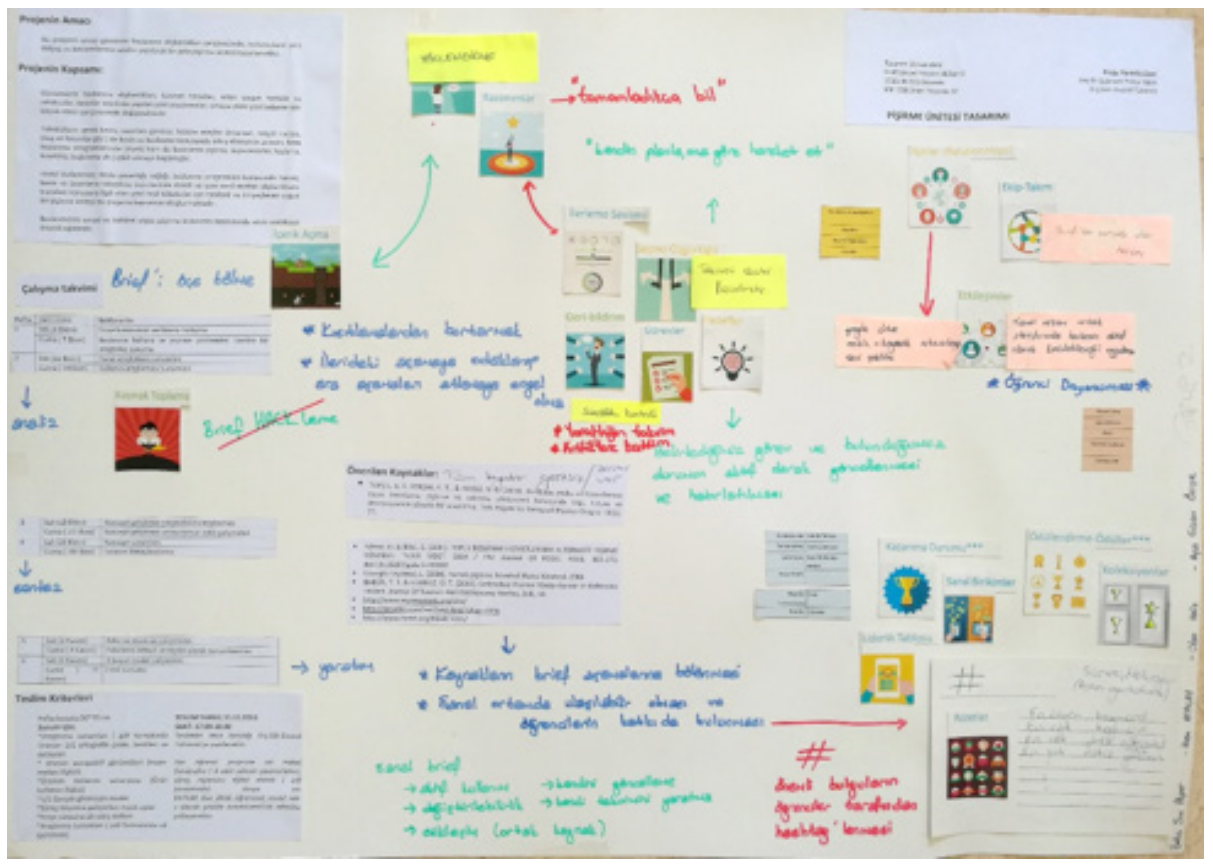

Figure 4. Second group poster presentation 
One of the important and interesting findings of the workshop is that this group defines as "hacking the brief" (in accordance with the new language of its own generation), that they vigilantly construct the design process due to the expected outcome of the process when all stages are shared at the same time on the design brief. As a result, the group, who thinks that they do not pass the design steps as efficiently as they would like to arrive fast, suggest that the briefing should be shared in turn by sharing the information of each step by dividing them under the titles of analysis, synthesis, and creation. The group stated that the resources should also be shared in order according to these stages, which is a limiting effect on the process.

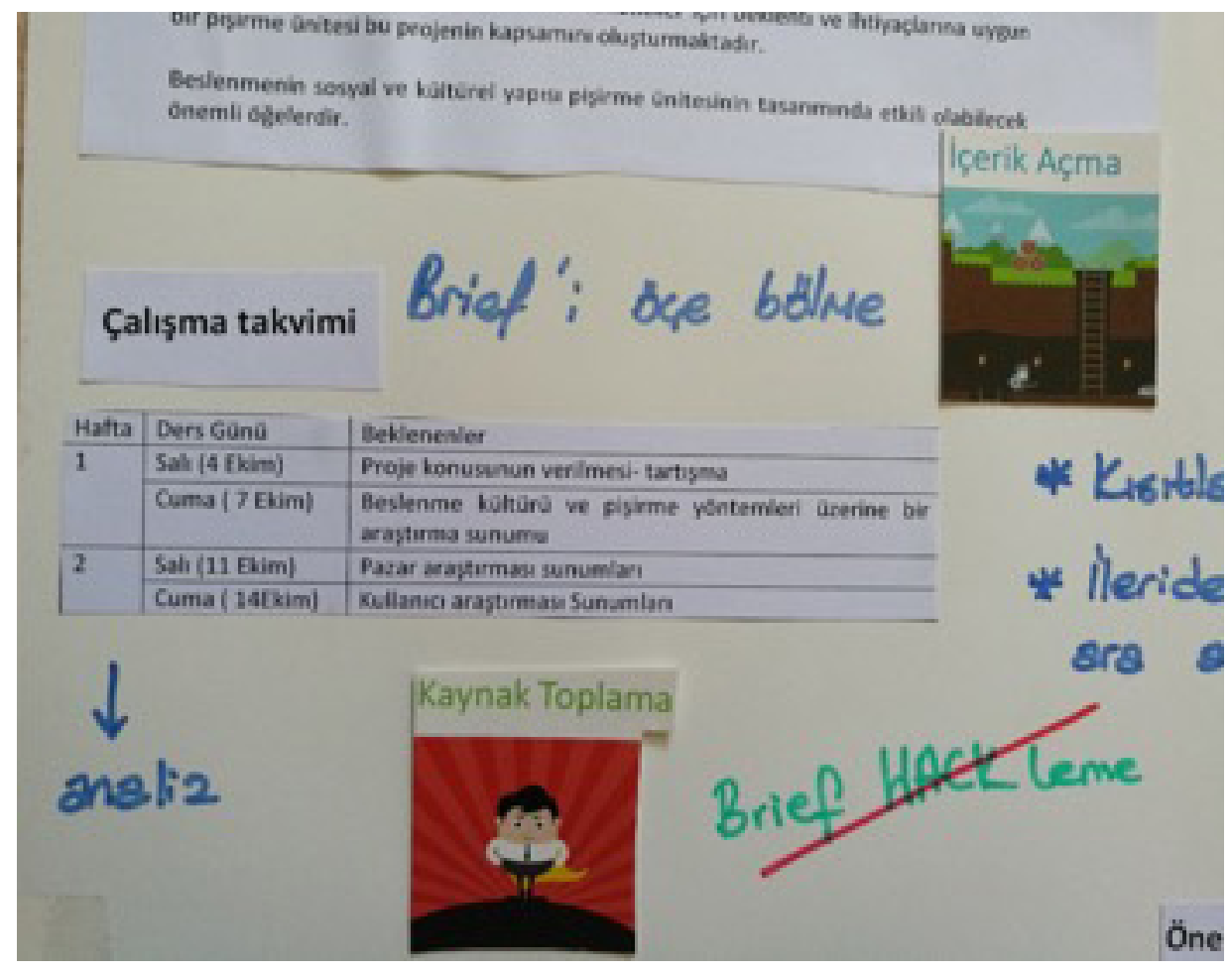

Figure 5. Hacking Brief

Group students expressed the basic expectation and proposal that the brief should take place in a digital environment. They have defined the advantages of the digital environment as the opportunity to reorganize and customize the brief.

They expressed the possibility of preparing individual programs in the work schedule as a result of sharing the Brief in a re-editable format or environment according to the expectations and needs of the students;

"We're fragmenting the brief, after that, you can create your own calendar. For example, let's say a student wrote his design phases, he will click on it if helhe complete, the system will remind like; "you have 3 days left" if helshe didn't complete. That reminder will always come like; you don't complete, complete... Not after everything is over, but in the process. "

Students have used the Achievements, Progressive Level, Freedom of Choice, Feedback, Mission and Goal cards in the personalized working calendar proposals. 


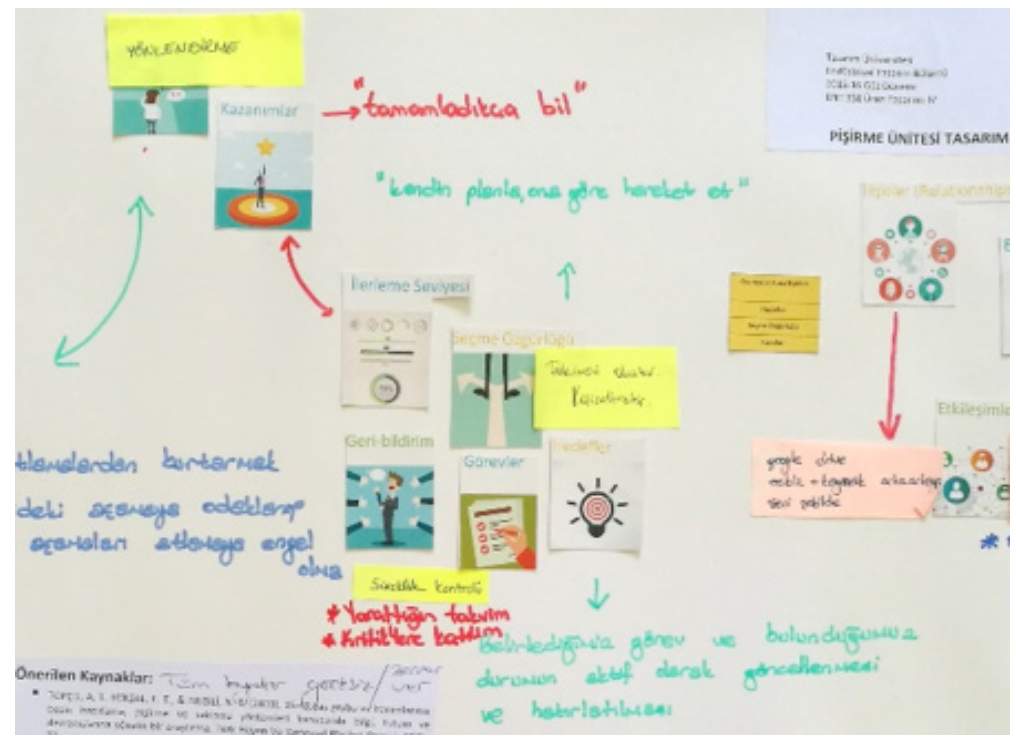

Figure 6. Personalized working calendar proposal

One of the important design proposals of the students has been a digital platform for the sharing of both personal work and general resources and documents related to the project. Digital medium examples like Pinterest, Google Drive, or social media accounts, where content is produced and shared are used to define the usage scenario of this new environment, as well as the Analysis and synthesis steps of the design process, have been prioritized. This expectation was expressed in a poster presentation using the Communication, Interaction, and Team Work cards together.

The group has used "hashtags", for shares to be made on this proposed digital platform, as represented by square marks (\#) in social media accounts or messages in a specific context. Also, in these proposals, (again with the usage of their own generations of specific language/jargon) if the shares reach a numerically specific target, they defined the badges to be earned depending on the share type as items motivating the process and motivating the students. The winning status, Virtual Savings, Rewarding-Rewards, Collections and Leadership Table cards, which are targeted to establish interaction based on sharing, are used. The Competition card emerges as a particularly coveted element of being used in all of the group's proposals

\section{Group Three}

A total of 4 students participated in this group. In the third group, a total of 11 concepts of gamification were used.

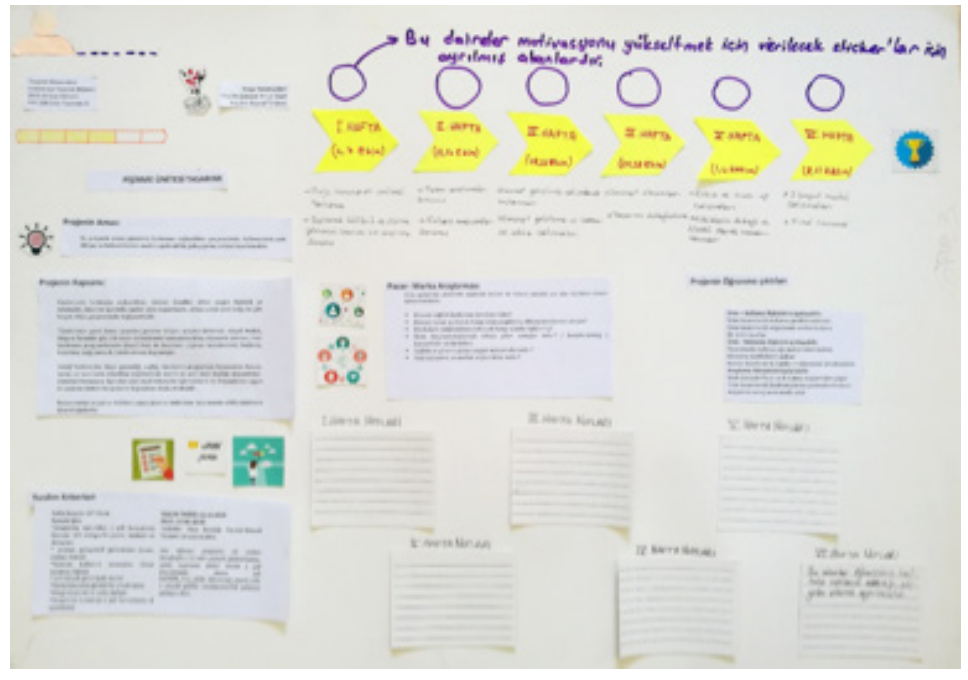

Figure 7. Third group poster presentation 
The third group started their presentation by saying the brief has become a personal tool for each of the students, a not for general use in the studio after it has been shared by academicians. The group spokesman stated this situation as follows;

"We started out from this point; brief is coming out of you and it comes to us, then it becomes ours... Here we are thinking of a persona... I could now write my notes here and it should be mine".

Despite the absence of an oral expression or visual element, the drawing on the presentation poster has been treated as an Avatar item. Students define the classes in the design education as "levels" and position them next to the personal visuals to visually express the studio lessons that the student has taken during his undergraduate studies and how much more project lessons he or she should take.

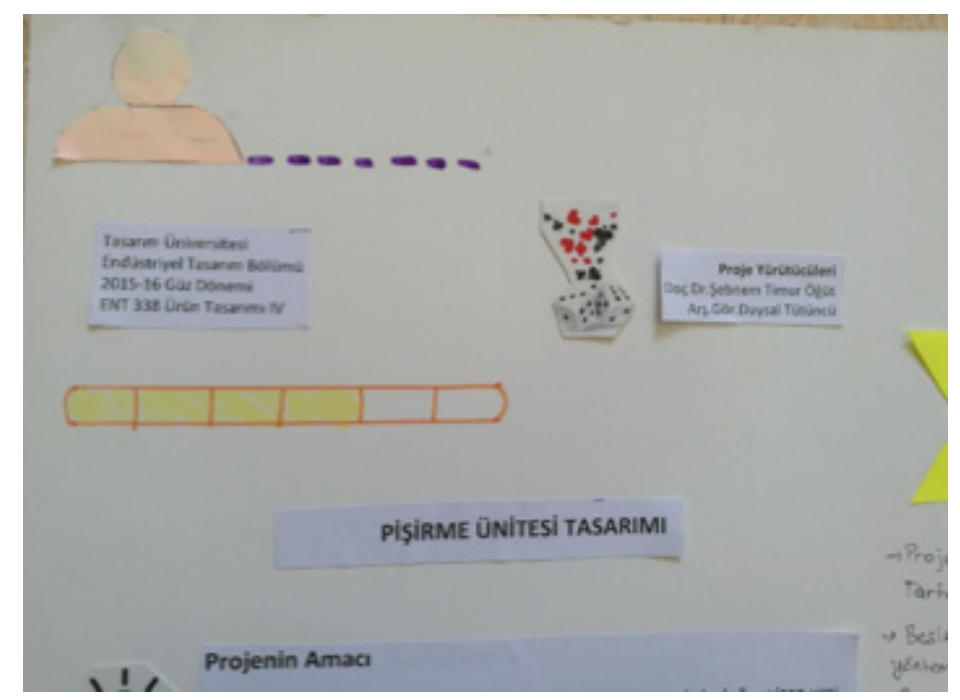

Figure 8. Customizable brief proposal with Avatar Card.

As regards the personalization of the Brief, the brief has been redesigned as a printed tool in which students can take notes associated with the course and create their own work plans during the course weeks. The students expressed these proposals as follows:

"Since Brief is ours now, we can use it as a notebook; to write down things came to our mind at that moment ... because we are underlining the words, we draw arrows on the edges of the paper. We take notes like I should do these this week or I have done that according to the weekly plan, take notes of important information we heard from the academician. We turned brief to a position that we always carry with."

Students have explained the main purpose of this proposal as a learner's ability to create his own work schedule and visualization of the progress of the process as a whole.

They used the card representing the Winning Status after the last week of the project in the working calendar. They have supported the work calendar with visual elements that will include the labels to be given as a result of the completion of the steps by the academicians. The students expressed the ultimate goal of these proposals:

"I need to see for self, like yes it is over...".

Students expressed the proposals for the reorganization of the Brief, which include scope, purpose and other items, while editing schedule with personalizable areas as follows;

"Not just to carry a paper, not just a paper, it can be something we can draw, we can write, we can take note of everything from week to week, something we can see our levels," 


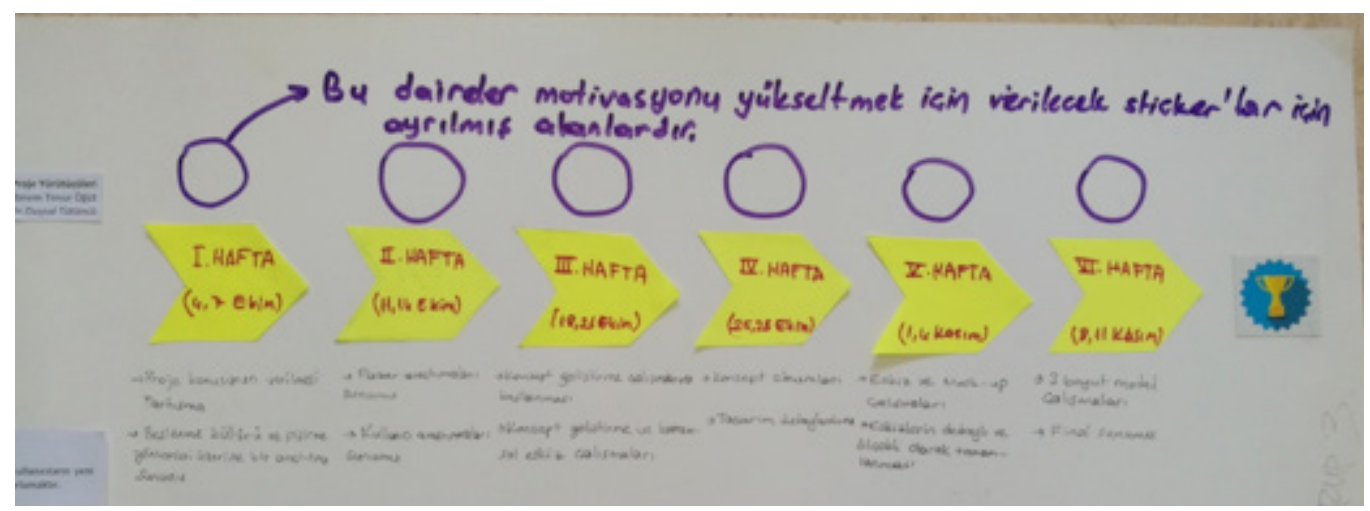

Figure 9. Students’ visual work calendar proposal

In the verbal discussion part, the students stated that all these elements used for brief proposals are a result of the requests to be followed by academicians in the process. One of the students stated that if the processes were not followed up, the process became complicated and the work to be done started to accumulate

\section{DISCUSSIONS AND CONCLUSION}

As stated in the previous sections, the aim of the workshop is not to design a new brief but to determine the expectations and needs of the incoming industrial design students based on the students' recommendations. This study, therefore, contributed to closing the gap in the current literature by focusing on exploring students' expectations and needs for the use of a digital and online learning tool in a special field such as design education while the literature generally focused on the testing of systems and applications designed in accordance with predetermined needs and expectations. As one of the important conclusions of CookSather's research (2014), participatory design processes have helped students explore different perspectives on their own learning experiences and explore the needs they had not previously been aware of.

The Gamification cards used in the workshop were used as a tool to enable students to discover and express their needs and expectations. The analysis of the students' poster presentations and the data obtained from the oral presentation and discussion sections were expressed in 9 different codes under the theme of expectations from the brief. The distribution of students' expectations in groups is presented in Table 2.

Table 2. Students' expectations from a brief

\begin{tabular}{llccc}
\hline \multirow{2}{*}{ THEME } & & \multicolumn{3}{c}{ FREQUENCY } \\
& CODES & GROUP1 & GROUP2 & GROUP3 \\
\hline & Portable transport & 1 & 0 & 1 \\
& To be placed in a digital environment & 2 & 3 & 0 \\
& Use of visual elements & 4 & 0 & 1 \\
Expectations & Make it possible for students to feel progress & 1 & 1 & 2 \\
from brief & Personalization & 0 & 2 & 1 \\
& Notification of learning status & 1 & 0 & 1 \\
& Allowing you to control the learning process & 0 & 1 & 1 \\
& Examples sharing & 2 & 1 & 0 \\
\hline
\end{tabular}

It seems that one of the basic expectations of the students is personalization. The personalization recommendation is expressed as leaving areas for the students to organize and change in the brief in line with their expectations and needs, as well as to make personal notes. The reorganization expectation is shared regarding the working calendar. Parallel to the stages of the design process shared by the academicians it is possible to create a work schedule in which students can place their own sub-goals. This finding is consistent with the findings of other studies which reported that personalized learning is one the key factors guiding 
basic needs and expectations of new generation learners in online learning environments (Afacan, 2018; Pektas \& Gurel, 2014).

The design proposal of the two groups has been related to the sharing of the brief in the digital environment. They have defined the advantages of the digital environment as the opportunity to reorganize and customize the brief. In addition to the fact that the work schedule can be rearranged by the students, sharing becomes an important theme.

The concept of sharing in the studio has been expressed in two different dimensions as sharing the resources that students have reached during the research process among themselves, sharing the sample images or documents related with the project by the academicians. Referring to the proposal for sharing resources by two of three groups it is understood that sharing during the early phases of design which expressed with different names like analysis-synthesis as a research phase, there is a belief that will have a positive impact on the design process. The possibility of accessing the resources contained in brief online was expressed as a very positive option by the students. This finding supports the finding reported by Pektas and Gurel (2014).

We can also consider the visual expectation of the students in the briefs in two dimensions; the shared resources or examples shared with them are expected to contain more visual elements, and the second relates to the use of more graphic elements or visuals with text on brief. This finding is parallel to Pektas and Gurel's research (2014) that revealed visual expectations of students in their LMS practice which the authors associate with the importance of "visual thinking" in design.

When we look at the expectations of learners in terms of learning management, it has been seen that expectations for visualization of the process immediately followed by a personalized work schedule proposal. The visual expression of situations related to learning, which is expressed by students as progressing, completing stages, or performing tasks, has been treated as a demand to follow their own learning processes.

The design education system continues to be accepted as an education system where face-to-face communication and hard copy printouts are used extensively in the studio. In the study, it was found that the idea of having the design brief in a digital environment motivates students to discover and express their special needs as well as physical interactions in the studio. This finding is consistent with the findings of other studies in related literature which reported the positive effects of the dualistic relationship between physical and virtual learning environments. (Afacan, 2018; Vignati, Fois, Melazzini, Pei, \& Zurlo, 2017).

\section{BIODATA and CONTACT ADDRESSES of AUTHORS}

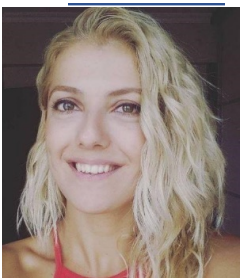

Dr. Duysal DEMIRBAS, works as research assistant at Eskisehir Technical University, Faculty of Architecture and Design, Department of Industrial Design. Dr. Duysal Demirbas had her doctoral degree in Industrial Product Design from Faculty of Architecture, Istanbul Technical University at 2018. Her research areas include design research, design education,furniture design and $\mathrm{R} \& \mathrm{D}$ through university-industry projects.

Duysal DEMIRBAS

Department of Industrial Design, Faculty of Architecture and Design, Address: Eskisehir Technical University, Iki Eylul Campus, 26555, Eskisehir, TURKEY

Phone: + 902223213550

E-mail: dtutuncu@eskisehir.edu.tr

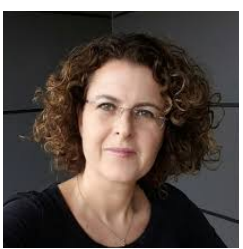

Dr. Sebnem TIMUR OGUT, is a Professor at Istanbul Technical University, Faculty of Architecture, Department of Industrial Product Design. Her research interests focus on industrial design, graphic design, design theories, design methods, semiotics, material and visual culture studies, ethnography and objects as cultural facts.

Sebnem TIMUR OGUT

Department of Industrial Product Design, Faculty of Architecture

Address: Istanbul Technical University, 34437, Istanbul, TURKEY

Phone: + $902122931300 / 2303$

E-mail: timurseb@itu.edu.tr 


\section{REFERENCES}

Afacan, Y. (2018). Student Experiences of Blended Learning in Interior Architecture. Journal of Information Technology Education: Research, 17, 399-422. https://doi.org/10.28945/4122

Ahn, H. (2007). Design Tools and Three Steps in Participatory Design Processes: A Proposal for Better Communications among Residents and Experts, based on a Case, Proceedings of the 6th Conference of the Pacific Rim Community Design Network. Retrieved from http://courses.washington.edu/ quanzhou/pacrim/papers/Ahn-Park-paper.pdf

Akademik Dersler - Tanitim. (n.d.). Retrieved December 22, 2016, from http://abp.anadolu.edu.tr/tr/ders/ $\operatorname{tanitim} / 95647 / 47$

Bedir Eristi, S. (Ed.). (2017). Gorsel Arastirma Yontemleri Teori, Uygulama ve Ornek [Visual Research Methods Theory, Applications and Examples] (2nd ed.). Ankara: Pegem Akademi.

Bergold, J., \& Thomas, S. (2012). Participatory Research Methods: A Methodological Approach in Motion. Forum Qualitative Sozialforschung / Forum: Qualitative Social Research, 13(1).

Buur, J., Binder, T., \& Brandt, E. (2000). Taking Video Beyond "Hard Data" in User Centered Design. Proceedings of the 6th Anniversary Conference on Participatory Design 2000, (December), 21-29. Retrieved from http://citeseerx.ist.psu.edu/viewdoc/summary?doi=10.1.1.89.3499

Cook-Sather, A. (2014). Multiplying perspectives and improving practice: What can happen when undergraduate students collaborate with college faculty to explore teaching and learning. Instructional Science, 42(1), 31-46. https://doi.org/10.1007/s11251-013-9292-3

Cokluk, O., Yilmaz, K., \& Oguz, E. (2011). Nitel Bir Gorusme Yontemi: Odak Grup Gorusmesi [ A Qualitative Interview Method: Focus Group Interview],Kuramsal Egitimbilim, 4(1), 95-107.

Demirbas, D., \& Timur Ogut, S. (2018). Design Briefs for Industrial Design Studio Courses: Determination of Expectations and Requirements. Journal of Qualitative Research in Education, 6(2), 42-58.

DiSalvo, B., Yip, J., Bonsignore, E., \& DiSalvo, C. (Eds.). (2017). Participatory Design for Learning: Perspectives from Practice and Research. Routledge. Retrieved from https://play.google.com/books/

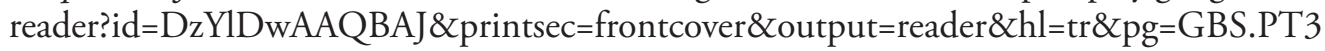

Hamari, J. (2013). Transforming homo economicus into homo ludens: A field experiment on gamification in a utilitarian peer-to-peer trading service. Electronic Commerce Research and Applications, 12(4), 236-245. https://doi.org/10.1016/j.elerap.2013.01.004

Hussain, S., Sanders, E. B. N., \& Steinert, M. (2012). Participatory design with marginalized people in developing countries: Challenges and opportunities experienced in a field study in Cambodia. International Journal of Design, 6(2), 91-109.

ICSID. (2015). WDO | About | Definition of Industrial Design. Retrieved June 21, 2017, from http://wdo. org/about/definition/

Jones, W. M., \& Askland, H. H. (2012). Design Briefs : Is There A Standard ? In Proceedings of the 14th International Conference on Engineering \& Product Design Education (pp. 115-121). Antwerp, Belgium: Artesis University College. Retrieved from https://www.designsociety.org/multimedia/ publication/88efc0feaaab5043e6a6b5fc489d0601.pdf

Kapkin, E. (2010). Endustriyel Tasarim Egitiminde Proje Tanimi Belgesinin Onemi ve icerik Ozelliklerinin Belirlenmesi: Turkiye Ornegi [Content Determination of the Design Brief and Its Importance in Industrial Design Education: Case Of Turkey], Anadolu Universitesi [Anadolu University] [Unpublished Master Thesis] Yayinlanmamis Yuksek Lisans Tezi

Kapp, K. (2012). The Gamification of Learning and Instruction: Game-Based Methods and Strategies For Training And Education. Pfeiffer. San Francisco.

Klopfer, E., Osterweil, S., Groff, J., \& Haas, J. (2009). Using the technology of today, in the classroom today.

Lawson, B. (2005). How Designers Think, The Design Process Demystified. Design Studies (5th ed., Vol. 2). Architectural Press. https://doi.org/10.1016/0142-694X(81)90033-8 
Luck, R. (2003a). Dialogue in participatory design. Design Studies, 24(6), 523-535. https://doi.org/10.1016/ S0142-694X(03)00040-1

Malinverni, L., Mora-Guiard, J., \& Pares, N. (2016). Towards methods for evaluating and communicating participatory design: A multimodal approach. International Journal of Human-Computer Studies, 94, 53-63. https://doi.org/10.1016/j.ijhcs.2016.03.004

Manzini, E., \& Rizzo, F. (2011). Small projects/large changes: Participatory design as an open participated process. CoDesign, 7(3:4), 199-215. https://doi.org/10.1080/15710882.2011.630472

Muntean, C. I. (2011). Raising engagement in e-learning through gamification. In The 6th International Conference on Virtual Learning ICVL 2011 (pp. 323-329).

Pedro, F. (2009). New Millennium learners in higher education: Evidence and policy implications. International Conference on 21st Century Competencies, Brussels: OECD/CERI.

Pedro, F. (2006). The New Millennium Learners: Challenging our Views on ICT and Learning. OECDCERI, (May), 1-17. https://doi.org/10.1017/CBO9781107415324.004

Pektas, S. T., \& Gurel, M. O. (2014). Blended learning in design education: An analysis of students' experiences within the disciplinary differences framework. Australasian Journal of Educational Technology, 30(1), 31-44.

Phillips, P. L. (2004). Creating the Perfect Design Brief. Canada: Allwort Press.

Prensky, M. (2001). Digital Natives, Digital Immigrants Part 1. On the Horizon, 9(5), 1-6. https://doi. org/10.1108/10748120110424816

Ryd, N. (2004). The design brief as carrier of client information during the construction process. Design Studies, 25(3), 231-249. https://doi.org/10.1016/j.destud.2003.10.003

Sanders, E. B.-N., Brandt, E., \& Binder, T. (2010). A framework for organizing the tools and techniques of participatory design. Proceedings of the 11th Biennial Participatory Design Conference on - PDC '10, 195. https://doi.org/10.1145/1900441.1900476

Sierra, W. (2013). Gamification as Twenty-First-Century Education. North Carolina State University.

Spinuzzi, C. (2005). The Methodology of Participatory Design. Technical Communication, 52(2), 163-174. https://doi.org/10.1016/j.infsof.2008.09.005

van den Hoven, J., Vermaas, P. E., \& van de Poel, I. (2015). Handbook of ethics, values, and technological design: Sources, theory, values and application domains. Handbook of Ethics, Values, and Technological Design: Sources, Theory, Values and Application Domains, 1-871. https://doi.org/10.1007/978-94007-6970-0

van Manen, S., Avard, G., \& Martínez-Cruz, M. (2015). Co-ideation of disaster preparedness strategies through a participatory design approach: Challenges and opportunities experienced at Turrialba volcano, Costa Rica. Design Studies, 40, 218-245. https://doi.org/10.1016/j.destud.2015.06.002

Vignati, A., Fois, L., Melazzini, M., Pei, X., \& Zurlo, F. (2017). E-LEARNING AND DESIGN PRACTICE. Tools and methods for professional learning of strategic design approach. The Design Journal, 20(sup1), S1026-S1036. https://doi.org/10.1080/14606925.2017.1353046

Visser, F. S., Stappers, P. J., van der Lugt, R., \& Sanders, E. B.-N. (2005). Contextmapping: experiences from practice. CoDesign, 1(2), 119-149. https://doi.org/10.1080/15710880500135987

Werbach, K., \& Hunter, D. (2015). The Gamification Toolkit: Dynamics, Mechanics, and Components for the Win. Wharton Digital Press.

Wolfel, C., \& Merritt, T. (2013). Method card design dimensions: A survey of card-based design tools. Lecture Notes in Computer Science (Including Subseries Lecture Notes in Artificial Intelligence and Lecture Notes in Bioinformatics), 8117 LNCS(PART 1), 479-486. https://doi.org/10.1007/9783-642-40483-2_34

Yilmaz, E. A. (2015). Oyunlastirma [Gamification]Istanbul: Abakus. 